\title{
Prevalence of Malnutrition among Children Aged 6-59 in Haramaya District, Oromia, Ethiopia
}

Fuad Redi'*, Gudina Egata² and Adem Kedir ${ }^{3}$

${ }^{1}$ Oda Bultum University, Dire Dawa, Ethiopia

${ }^{2}$ Haramaya University, Ethiopia

${ }^{3}$ Arsi University, Ethiopia

\begin{abstract}
Malnutrition is a general term for a medical condition caused by an improper or insufficient diet. Under nutrition is prevalent around the world. The objective of this study was to assess the prevalence of under nutrition and factors affecting nutritional status among children aged 6-59 months in Haramaya, eastern Ethiopia. The data were collected by using a well-structured pretested questionnaire. Anthropometric measurements of the children were taken to assess the nutritional status of the children. The prevalence of stunting, wasting and underweight were $36.07 \%$ [ $95 \% \mathrm{Cl}(0.314$ $0.408)], 14.43 \%[95 \% \mathrm{Cl}(0.110,0.179)]$ and $23.63 \%$ [95\% Cl $(0.195,0.278)]$, respectively. The current study showed that the prevalence of child under-nutrition is highly prevalent in Haramaya district. Community based nutrition program should be established; continuous nutrition supervision based on each nutritional status indicators and special attention to severely malnourished children is necessary to attempt the problem of malnutrition.
\end{abstract}

Keywords: Haramaya; Z score; Under-nutrition; Prevalence; Underweight; Stunting; Wasting

\section{Introduction}

Malnutrition is a general term for a medical condition caused by an improper or insufficient diet. The term usually refers to generally bad or faulty nutrition and is most often related to under nutrition. According to the World Health Organization (WHO), malnutrition is the cellular imbalance between supply of nutrients and energy and the body's demand for them to ensure growth, maintenance and specific functions, and was the greatest risk factor for illness and death worldwide [1].

Under nutrition was prevalent around the world. Despite numerous advances in medicine and clinical care, the simple correction of nutritional status of individuals appears to be overlooked or not considered as a sufficient medical priority [2].

According to FAO's most recent estimates indicated those above $98 \%$ of hungry people in the world live in developing regions. SubSaharan Africa had the highest prevalence of undernourishment and too little progress of decreasing the number of hunger people in both northern and sub-Saharan parts of the continent [3].

Also United Nations Children's Funds (UNICEF) globally estimated that about 165 million (26\%), 101 million (16\%) and 52 million (8\%) of children under 5 were stunted, underweight and wasted respectively in 2011. In sub-Saharan Africa 40 per cent of children under five were stunted, 33 per cent were underweight and the number of wasted under five children was increasing through time to time [4].

Ethiopian Demography and Health Survey revealed that about $44 \%$ of under five children were stunted, $29 \%$ were underweight and $10 \%$ were wasted in 2011 . In Oromia region prevalence of child under nutrition indicates that $26 \%$ were underweight with $7.8 \%$ severe underweight, $9.7 \%$ of the children were wasted with $2.8 \%$ severe wasting and $41.4 \%$ of the children were stunted with $18 \%$ severe stunting [5]. A community based study conducted on prevalence of malnutrition and associated factors among children aged 6-59 months at Hidabu Abote District, Oromia, in 2013 revealed that $47.6 \%, 30.9 \%$ and $16.7 \%$ of children were stunted, underweight and wasted respectively [6]. But, Ethiopian demographic and health survey did not present the problems associated with nutritional status of children on district level, and the study in a district might not represent other district. Therefore, the objective of this study was to assess prevalence of under-nutrition among children aged 6-59 months in Haramaya district.

\section{Methods and Materials}

\section{Study area, period and design}

A community based cross-sectional study design was used in Haramaya district, East Hararghe Zone, Ethiopia from January 05 to March 25, 2015. Haramaya district was located $506 \mathrm{~km}$ far from East of Addis Ababa. The elevation of the area was about $2000 \mathrm{~m}$ above sea level and geographically it located 041 ${ }^{\circ} 59^{\prime} 58^{\prime \prime}$ latitude and $09^{\circ} 24^{\prime} 10^{\prime \prime}$ longitudes. The district receives an average annual rain fall approximately $900 \mathrm{~mm}$ and climatically there were two environmental zones of which $66.5 \%$ was midland and $33.5 \%$ was lowland. According to CSA population projection for 2014 out of the total population in Oromia region, 32,815,995, about $10 \%$ was located in East Hararghe Zone. In the Haramaya district the projected population for 2014 was 332,985 and about $79 \%$ of the total population in the district was located in rural area [7]. The number of under five children in the district was about 72978 and above $87 \%$ of the children was located in the rural area. In the district there was one hospital, seven health centres and 34 health posts. About 78 health workers were recently working in the health posts in the district. The district was divided into 33 rural and 4 urban kebeles.

\section{Sample size determination and sampling techniques}

Population: The source population was all children aged between

*Corresponding author: Redi F, Lecturer in Oda Bultum University, Ethiopia, Tel: +251 92592 0594; E-mail: redifuad@gmail.com

Received January 17, 2017; Accepted July 29, 2017; Published August 07, 2017

Citation: Redi F, Egata G, Kedir A (2017) Prevalence of Malnutrition among Children Aged 6-59 in Haramaya District, Oromia, Ethiopia. J Biom Biostat 8: 357. doi: 10.4172/2155-6180.1000357

Copyright: (c) 2017 Redi F, et al. This is an open-access article distributed under the terms of the Creative Commons Attribution License, which permits unrestricted use, distribution, and reproduction in any medium, provided the original author and source are credited. 
6 and 59 months and their mothers or care givers in Haramaya district. The sample population was all randomly selected children aged 6-59 months in the selected kebeles of Haramaya district. This study included children in the district aged between 6 and 59 months capable to be measured, not hospitalized for sickness, and whose mothers or caregivers willing to be interviewed. The children who were severely injured by accidents or hospitalized and whose mother/caregivers were not physically and mentally capable to be interviewed and not willing to be interviewed were excluded from this study.

Sampling techniques: The sampling technique used in this study was two stages stratified sampling method. The residence of the household in the district as rural and urban kebeles considered as strata. At the first stage, kebeles were selected from rural and urban residences by using simple random sampling. Four kebeles from the rural kebeles and one kebele from urban kebeles selected randomly. At the second stage, children who were aged between 6 and 59 months selected randomly in each selected kebeles. The rural kebeles included in this study were Finkille, Efa Bate, Damota and Karo Dada, and among four urban kebeles Adelle was randomly selected. The number of children randomly selected from Finkille, Efa Bate, Damota and Karo Dada, was 112, 56, 119 and 63 respectively. Among four urban Kebeles, Adelle was included in the study, and 52 children were randomly selected (Figure 1).

Sample size determination: The sample size determined by using proportion for stratified sampling technique formula and proportional to size allocation method [8].

Firstly initial sample size was calculated as:

$$
n_{0}=\sum_{h=1}^{2} \frac{W_{h} p_{h} q_{h}}{d^{2} / t^{2}}=\sum_{h=1}^{2} \frac{W_{h} p_{h} q_{h}}{V}, h=1,2 .
$$

\section{Where}

$\mathrm{n}_{0}=$ Initial sample size.

$\mathrm{t}=$ the standardized normal distribution value at $95 \%$ level of significance. $\mathrm{pH}$.

$\mathrm{pH}=$ prevalence of stunting in urban and rural residences, $\mathrm{q}_{\mathrm{h}}=1$ -

$\mathrm{d}=$ margin of error $=5 \%, V=\frac{d^{2}}{t^{2}}=0.00065$.

$\mathrm{W}_{\mathrm{h}}$ is the stratum weight, $\mathrm{W}_{1}=$ the weight of rural residence $=0.87$, $\mathrm{W}_{2}=$ the weight of urban residence $=0.13$.

In this study the value of $\mathrm{pH}$ was taken from Ethiopian Demographic and Health Survey in 2011 that the prevalence of stunting for rural was

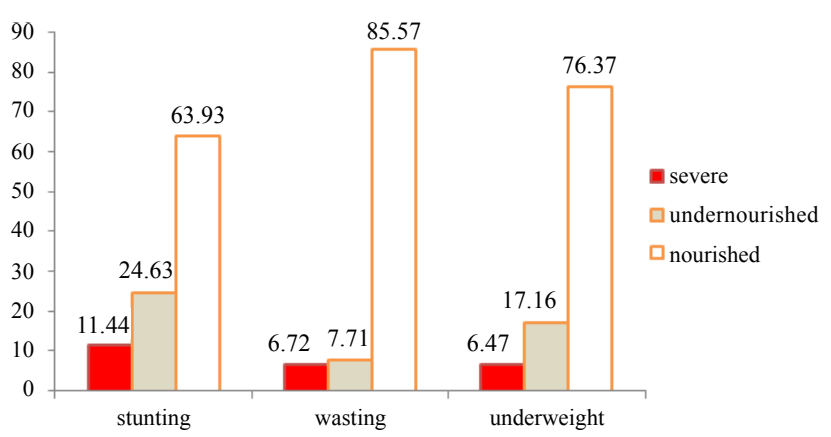

Figure 1: Nutritional status of children aged 6-59 months by percent in Haramaya district from January 05 to March 25, 2015.
$46.2 \%$ and for urban was $31.5 \%$, the value of $\mathrm{W}_{\mathrm{h}}$ calculated by using the total number of under five children in the district and the total number of children in the residences. The initial sample size and total sample size was computed as:

$$
n_{0}=\sum_{h=1}^{2} \frac{W_{h} p_{h} q_{h}}{V} \approx 377
$$

By considering non response rate $10 \%$, the sample size calculated for this study was 415 . The next step was allocating the sample size to different residences by proportional to size allocation method (Table 1).

After the selection of kebeles the number of children selected from each randomly selected kebeles allocated by using proportional to size allocation method in Table 2.

Data collection and processing: The data type in this study was primary data and obtained by using well-structured questionnaires. The questionnaire was initially prepared in English and translated into the local language, "Afan Oromo", by fluent speakers of both languages.

Experienced health workers who able to communicate in "Afan Oromo" and employed from Haramaya district or nearby other districts sited in the study area for data collection based on their experience on data collection, and supervisors employed. Interviews were conducted with mothers/caregivers of the children to fill the questionnaire. To ensure the quality of data, training was given for the data collectors on the objective of the study and methods of data collection, anthropometric measurement and data recording methods. The supervisors and researcher closely followed the day to day data collection process and ensure completeness and consistency of the collected questionnaires on a daily basis.

The anthropometric data were measured based on the procedure stipulated by the WHO [9] for taking anthropometric measurements. Before taking anthropometric data for children; their age should be first determined in order to ensure the target population. The mothers were asked the age of child and if age cannot be determined accurately a height of $60-110 \mathrm{~cm}$ was considered as proxy indicators, the children his/her mother cannot remember the age, if the height of child was out of this range he/she should be excluded from the study.

Body length of children age up to 2 years, who could not able to stand, was measured without shoes and the height was read to the nearest $0.1 \mathrm{~cm}$ by using a horizontal wooden length board with the infant in recumbent position. However, heights of children 2 years and above were measured using a vertical wooden height board by placing

\begin{tabular}{|c|c|c|}
\hline Residence & $\begin{array}{c}\mathbf{W}_{\mathbf{i}} \text { (weight of each } \\
\text { stratum) }\end{array}$ & $\begin{array}{c}\text { Sample size (number of under-five } \\
\text { children in the study) }\end{array}$ \\
\hline Rural & 0.87 & 361 \\
\hline Urban & 0.13 & 54 \\
\hline Total & 1.00 & 415 \\
\hline
\end{tabular}

Table 1: Sample size allocation in rural and urban areas in Haramaya district in January 2015

\begin{tabular}{|c|c|c|c|}
\hline $\begin{array}{c}\text { Name of the } \\
\text { Kebeles }\end{array}$ & $\begin{array}{c}\text { Number of under five } \\
\text { children }\end{array}$ & Weight $\left.\mathbf{( W}_{\mathbf{i}}\right)$ & Sample Size \\
\hline Finqille & 1673 & 0.32 & 115 \\
\hline Damota & 1778 & 0.34 & 123 \\
\hline Karro Dada & 941 & 0.18 & 65 \\
\hline Efa Bate & 836 & 0.16 & 58 \\
\hline Total & 5228 & 1.00 & 361 \\
\hline
\end{tabular}

Table 2: Allocation of sample size in selected Haramaya rural kebeles in January 2015. 
the child on the measuring board, and child standing upright in the middle of board. The child's head, shoulders, buttocks, knees and heels should be touching the board. The weight of the children was measured by electronic digital weight scale with minimum clothing and no shoes [10]. Adjusting the instrument was done before weighing every child by setting it to zero. The children who were less than two years and not suitable for measuring their weight alone were measured by measuring the mother and children together, and then subtracting the weight of the mother to obtain the weight of the children [11].

Oedema was checked and noted on data sheet because children with oedema were severely undernourished. In order to determine the presence of oedema, normal thumb pressure applied to the two feet for three seconds whether a shallow print or pint remained on both feet when the thumb was lifted. To identify retrospective morbidity of children, mothers were asked about any occurrence of illness during the past two weeks. Vaccination status of children was checked by observing vaccination card and if not available mothers asked to recall it. MUAC was measured on left mid upper arm and the result was recorded for both children and their mothers.

Child under nutrition could be identified in several ways. It was most commonly assessed through measurement of a child's weight and height, as well as through biochemical and clinical assessment. Indicators based on weight, height and age were compared to international standards and were most commonly used to assess the nutritional status of a population. Stunting captures early chronic exposure to under nutrition; wasting captures acute under nutrition; underweight was a composite indicator that includes elements of stunting and wasting (UNICEF, 2013). The advantage of anthropometry was that body measurements were sensitive over the full spectrum of malnutrition [12]. Anthropometric measurement was a widely used, inexpensive and non-invasive measure of the general nutritional status of an individual [10]. In this study the data collected to assess the nutritional status of children by measuring the height and weight of all children aged between 6 and 59 months.

The height-for-age index provided an indicator of linear growth retardation and cumulative growth deficits in children. Children whose height-for-age Z-score was below minus two standard deviations from the median of the WHO reference population indicates stunting, or chronically malnourished. Children who were below minus three standard deviations indicate that severely stunted. Stunting reflects failure to receive adequate nutrition over a long period of time and was affected by recurrent and chronic illness.

The weight-for-height index measures body mass in relation to body height or length; it describes current nutritional status. Children with Z-scores below minus two standard deviations indicates that the child was thin (wasted) or acutely malnourished. Wasting represents the failure to receive adequate nutrition in the period immediately preceding the survey and may be the result of inadequate food intake or a recent episode of illness causing loss of weight and the beginning of under-nutrition. A child with a weight-for-height index below minus three standard deviations indicates that the child was severely wasted. The weight-for-height index also provides data on overweight and obesity. Children more than two standard deviations above the median weight-for-height were overweight.

Weight-for-age was a composite index of height-for-age and weightfor-height. It takes into account both chronic and acute malnutrition. A child can be underweight for his/her age because he or she was stunted, wasted, or both. Weight-for-age was an overall indicator of a population's nutritional health. Children with weight-for-age below minus two standard deviations were classified as underweight. Children with weight-for-age below minus three standard deviations were severely underweight.

To determine the $\mathrm{z}$ score of anthropometric measurements of the children based on WHO standards for each of three indicators the data imported to WHO Anthro software. The prevalence of stunting, underweight and wasting for under-five children in the study area estimated based on anthropometric data obtained from the study population.

Ethical consideration: Office of health department in the study area was communicated through letters from Haramaya University Department of Statistics. Letters of permission obtained from Haramaya Wereda health office and Offices at lower levels in the study area communicated through letters from health office of Haramaya Wereda. Oral informed permission taken from each mother prior to the interview and anthropometric measurement of children done after the purpose of the study explained to them.

\section{Result and Discussion}

According to the WHO [9] reference standard taking two standard deviations as cutoff point, the $\mathrm{z}$ score of the study subject who fails below minus two standard deviation was taken as stunted, wasted and underweight. The prevalence of stunting, wasting and underweight were $36.07 \%$ [ $95 \%$ CI $(31.4 \%, 40.8 \%)$ ], 14.43\% [95\% CI (11.0\%, 17.9\%)] and $23.63 \%$ [95\% CI $(19.5 \%, 27.8 \%)]$, respectively. Prevalence of severe stunting, wasting and underweight was $11.44 \%$ (95\% CI [8.3\%, $14.6 \%]), 6.72 \%$ (95\% CI [4.3\%, 9.2\%]) and 6.47\% (95\% CI [4.1\%, $8.9 \%])$ respectively (Figure 1).

This study shown that malnutrition was a problem in Haramaya District whereby it affects children 6-59 months age as measured by the three indicators (underweight, stunting, and wasting). The prevalence of stunting, wasting and underweight were $36.07 \%$ [95\% CI $(0.289,0.382)], 14.43 \%$ [95\% CI $(0.081,0.143)]$ and $23.63 \%$ [95\% CI $(0.169,0.249)]$ respectively. Prevalence of severe stunting, wasting and underweight was $11.44 \%$ [95\% CI $(0.066,0.124)], 6.72 \%$ [95\% CI $(0.017,0.055)]$ and $6.47 \%$ [95\% CI $(0.023,0.064)]$, respectively. The current study revealed that child age, child sex, diarrhea infection, employment status of the mother, and household food security status were important factors of all three indicators of nutritional status of the children. Wealth quintiles were significantly related to the $\mathrm{z}$ score of underweight and wasting of the children. The frequency of child feeding per day was significant predictor to the $\mathrm{z}$ score of stunting and underweight of the children. The significant factor of the $\mathrm{z}$ score of stunting and wasting jointly was the residence of household.

In the current study the prevalence of stunting among under five children was higher than a study conducted in Gimbi district, Oromia region $32.4 \%$ stunted and the prevalence of underweight and wasting slightly equal; 15.9 percent of the children were wasted, and 23.5 percent underweight [13]. Although the result in this finding is less than the study conducted on the prevalence of malnutrition of children age 36-72 months in Gobu Seyo district which was $49.0 \%$ stunted [14]. This difference might be due to study period and study area, in the current study data was collected in January when most rural areas have no shortage of food relative to summer session.

EDHS 2011 indicated that the prevalence of stunting, underweight and wasted were $44 \%, 29 \%$ and $10 \%$ among children age 6-59 months respectively. The findings of the current study were less prevalence 
of stunting and underweight, however the prevalence of wasting was higher with $36.07 \%$ stunting, $23.63 \%$ underweight and $14.3 \%$ wasting. This difference might be occurred due to the period of data collection.

\section{Conclusions and Recommendations}

The current study showed that malnutrition is highly prevalent in Haramaya District. Community based nutrition program should be established; continuous nutrition supervision based on each nutritional status indicators and special attention to severely malnourished children is necessary to attempt the problem of malnutrition. The governmental bodies in national level are obliged to accountability for ensuring that nutrition is sufficiently reflected in policies, strategies and legislation; at district level the implementation of policies and strategies within districts should be ensured.

\section{References}

1. Nikolaos K, Charilaos D, Meropi K, Evangelia M, Kalliopi AP (2010) Clinica Nutrition in Practice. A John Wiley and Sons, Ltd., Publication, Athens, Greek.

2. Lisa AB, Belinda SG, Timothy CC (2011) Hospital Malnutrition: Prevalence, Identification and Impact on Patients and the Healthcare System. Int J Environ Res Public Health 8: 514-527.

3. FAO (2012) The state of food insecurity in the world 2012. Economic Growth is necessary but not sufficient to Accelerate Reduction of Hunger and Malnutrition (FAO) Rome, Italy 1-61.

4. UNICEF (2013) Improving child nutrition. The achievable imperative for global progress New York, USA.
5. Central Statistical Agency (2012) Ethiopia Demographic and Health Survey 2011. Addis Ababa, Ethiopia.

6. Kebede M, Kassahun A, Bikes D (2013) Prevalence of malnutrition and associated factors among children aged 6-59 months at Hidabu Abote district, North Shewa, Oromia Regional State, Gondar University, Ethiopia. J Nutr Dis Ther

7. Central Statistical Agency (2013) Population Projection of Ethiopia for All Regions at Wereda Level from 2014 - 2017. Addis Ababa, Ethiopia.

8. Cochran W (1977) Sampling Techniques, (3rd edn.), John Wiley and Sons, Inc. Harvard University, New York, USA

9. World Health Organization (2006) Multicentre growth reference study group WHO Child Growth Standards based on length/height, weight and age. Geneva, Switzerland

10. Cogill B (2003) Anthropometric Indicators Measurement Guide. Food and Nutrition Technical Assistance Project, Academy for Educational Development Washington DC, USA.

11. Adelheid WO, de Onis M (2008) WHO child growth standards: training course on child growth assessment. World Health Organization, Geneva, Switzerland.

12. Blossner M, de Onis M (2005) Malnutrition: Quantifying the health impact at national and local levels. Environmental Burden of Disease Series, No: 12 WHO Geneva, Switzerland.

13. Kebede Eticha (2007) Prevalence and Determinants of Child Malnutrition Gimbi district, Oromia Region, Ethiopia. Addis Ababa University, Addis Ababa, Ethiopia.

14. Gemede FH, Tolera G, Wirtu D (2014) Prevalence of wasting and associated factors among preschool children in Gubo Sayo, East Wollega, Ethiopia. Food Science and Quality Management 28. 